have been born despite the drunkenness until the mother has been broken down. ${ }^{18}$ Drunkenness of the father at the time of impregnation may produce defectives through the resultant shock to the mother.

While the direct inheritance of minor defects is rare, its rarity is much overestimated. Prepuce absence among Jews is so frequent that a special volume of Rabbinical lore ${ }^{1 y}$ deals with the controversies over the ritual to be used in case a child is born without a prepuce. The infrequency of such cases among non-circumcising races needs no demonstration. Ritual circumcision occurs during the formative stage of sexual development. The allegation of the abscence of inherited effects from ritual circumcision is sheer assumption, repeated for decades without attempts at demonstration. The religious literature on the subject alone demonstrates this since theologians do not meet a ritual difficulty until it arises. ${ }^{20}$ Tests of the malignity or benignity of heredity are often very erroneous. A large family is assumed to be decided evidence against degeneracy. It is often a transformation of malign hereditr. As Herbert Spencer has shown, with increase in growth and specialization, decrease in the explosive manifes'ations of life must occur. Among these explosive manifestations in early biologic history is the function of reproduction which is common to all cells. With advance in evolution th. functions of cells become specialized and the evtent of reproductive power is decreased. This snecialization Spencer designates individuation. In degeneracy the organism returns to the lower type and consequently tends to a reversion of individuation. From this results the plural and frequently repeated births in the phthisical and the degenerate. Valenta had under observation two epileptics (mother and daughter) who illustrated very decidedly the biologic stigma to which reference has just been made. The mother had thirty-eight children--six times twins, four times triplets, and twice quadruplets. The daughter at the age of 40 had had thirtytwo children; three times twins, six times triplets, and twice quadruplets. Ninety families of degenerates coming under my own observation averaged eleven children each. Triplets, quadruplets, and twins were more than ten times as frequent as among the population taken as a whole. The occurrence of large families is not an expression of advance but of degeneracy. The teachings which have been entirely too prevalent as to the status in evolution being determined by progeny have cultivated what must be regarded merely as one transfnrmation of malign heredity. Another biologic stigma of degeneracy on which considerable stress is laid as an evidence of health is the occurrence of one instance of old age in a family of short-lived people. In biology of degenerates such instances are remarkably frequent. In this instance, while there is an expression of healthy atavism, there is also an expression of degeneracy which. predisposing the organism to yield to slight causes of disease, thereby prevents it from being deeply affected by them. On the other hand the absence of any deep emotional feeling enables such an organism to ride through worry like a cork through an ocean storm, and thereby to survive.

It is obvious that the problem of heredity has been approached from the standpoint of preconceived notions. The forces underlying it have been estimated entirely from the standpoints of times when embryology and biology were unknown. Furthermore, certain forces have been regarded as malign or benign per se when circumstanees made them so. The tests of malignity or benign- ity have also been based on preconceived notions. Decrease or increase of births has been estimated entirely from a fallacious view-point.

BIBLIOGRAPHX:

1. Maladies Mentales.

2. La Psychologie Morbide.

3. The Journal A. M. A., xxxi, p. 1311.

4. Der Kampf der Theile im Organismus.

5. Geddes-Thomson: Evolution of Sex.

6. Medicine, 1900.

7. Essays on Heredity.

8. A. H. Thompson: Dental Cosmos, 1874.

9. Moore: Evolution by Atrophy.

10. Alexander, Harriet C. B.: Medicine, 1896.

11. Germ I'lasm, p. 389.

12. Ibid., p. 387 .

13. Medicine, 1897

14. Proceedings Brit. Zoologic Soc., 1868.

1.5. Gaillard's Med. Journal, 1883.

16. Sensation et Mouvement.

17. Somatic Etiology of Insanity, 1877.

18. Neurologic Contributions, vol. 1

19. The Medrash.

20. L. S. Talbot: Medicine, 1898.

\section{NOTE ON GAUGING VESICAL CAPACITY.} G. FRANK LYDSTON, M.D.

I'rofessor of Genito-Urinary Surgery, State University of Illinois Professor of Surgery, Chicago Clinical School. CHICAgo.

The determination of the capacity of the bladder is often a very important point in the study and treatment of vesical disease. While the amount of urine that the bladder will retain without serious discomfort is by no means an infallible criterion of the extent of vesico-parietal pathologic alterations, it is nevertheless often of positive value from that standpoint. As indicative of the progress of certain cases under treatment it is often invaluable. As indicating the relative degree of impairment of elasticity of the bladder walls and the presence, degree and progress of pericystitis, the capacity of the bladder is one of the most important points for the consideration of the surgeon. The ordinary method of injecting the bladder hydrostatically -as with the fountain syringe or glass irrigating apparatus, with or without catheter or tube-is open to serious impeachment on the grounds of inaccuracy. The reasons for this inaccuracy I will venture to present.

1. In case the catheter or tube is used, the urinary besoin is excited by the presence of the tube in the deep urethra, vesical neck and cavity. Under these circumstances it is impossible to determine whether an imperative desire to urinate as the bladder is filled, is due to extreme physiologic distension, or to reflex excitation of vesical contraction through irritation of the seat of urinary desire by the catheter, which acts simply as might any foreign body.

2. When a large catheter is used, unless the hydrostatic pressure is too low to overcome the true sphincter and distend the bladder at all, the water rushes into the bladder so rapidly that the bladder is literally "surprised" into a reflex resentment of the inflowing fluid, and its capacity is transiently so diminished thereby that it is often less than half the normal capacity for urine. A bladder which will tolerate the presence of 8 or 10 ounces of urine under ordinary conditions often resents the pressure of 4 to 6 ounces of sterilized water by the irrigating method. When the urine trickles into the bladder guttatim, or enters per saltum from the ureters, the bladder is distended very gradually, and a relatively large amount of urine will be tolerated without discomfort. Half the same quantity of fluid thrown into the bladder rapidly will often necessitate immedi- 
ate evacuation of the viscus. It would seem that bland and neutral urine should be better tolerated than the average acid normal urine, but I have made some very interesting observations on this point. In persons who are ingesting large quantities of pure spring water, which passes through the renal mechanism very rapidly, the bladder capacity is often immediately markedly decreased. This is due to the extreme rapidity with which the urine enters the bladder even though it be per vias naturales. I have noted this phenomenon so often that I feel sure of my ground. Irritable bladders can be, and often are, injuriously overworked in this way. When the hydrostatic method is employed without tube or catheter, the amount of force necessary to overcome sphincteric resistance foreordains a relatively powerful, bulky and swiftly-running current. This awakens bladder resentment both from stimulation of the urinary besoin, and surprising the bladder muscle, and speedy evacuation becomes necessary. This explains why so few accidents happen from hydrostatic expansion of the bladder. The bladder contracts and expels the fluid before hyperdistension occurs. This protective reflex is, however, not to be trusted too far. Its reliability presupposes a fairly sound and fairly elastic bladder wall. Caution is therefore necessary in aged subjects, whether the bladder is known to be extensively diseased or not.

There is no routine method for measuring bladder capacity which is applicable to all cases. Symptomatically, cases may be divided into those in which the abnormal calls to urinate are worse at night, and second. those in which the greatest frequency is during the waking hours. In the first class of cases the symptom-producing condition is almost entirely organic. In such cases the environment of daytime life is more or less distracting, and the calls to urinate are not so frequent as at night. In the second class there is a greater or less degreee of neuropathic disturbance, existing either as a complication of actual organic disease and subordinate to it, or constituting - as it often does- the overshadowing element of the case. It is often difficult to draw the differential diagnostic lines, it is true; yet the cases in which it can be done are by no means infrequent. In cases with a decided neuropathic bias, the patient is unduly concerned about his bladder symptoms, and as a result of auto-suggestion the frequence of urinary desire is increased. Few realize how important the neuropathic side of urinary disturbances often is. A physician of my acquaintance who is the unfortunate possessor of an irritable bladder, tells me that his condition is almost unbearable when he happens to have in hand cases in which the disturbance of micturition is a strong factor.

Even in cases in which the condition is obviously organic there may be a neuropathic element, as a consequence of which micturition is most frequent in the daytime. In general, however, increased diurnal freqiency means conditions in which movement and gravity enhance the local irritation. This is often found in prostatiques, vesical tumor and calculus. In general, frequent micturition due chiefly to inflammatory conditions is improved by rest, nocturnal or diurnal.

In cases of a purely nervous type, or in which the nervous element is a serious factor for considerationcases distinguished clinically by lessened frequency of micturition at night-and in certain organic conditions in which rest is productive of similar improvement in symptoms, the capacity of the bladder can be gauged by a method at once simple and efficient, a method which does not err by proving only the capacity of the bladder while in hyperdistension. The patient should be instructed to drink moderately of pure water during the evening, and, when aroused at night by a desire to micturate, to pass water on each occasion in a separate vessel. The greatest quantity obtained at any given micturition represents the maximum capacity of the bladder from a clinical standpoint. Cases in which the frequency of urination is aggravated at night, can not be gauged in this way, and mechanical means must necessarily be employed. The chief ource of error here is: 1. hyperesthesia of the prostatic urethra and consequent exaltation of the urinary besoin; 2, too rapid distension of the bladder, producing "surprise" and peremptory muscular reflex in the bladder wall.

These sources of error being understood, the practical deductions are at once obvious. In the first place, general reflex excitability, if marked, should be guarded against by sedatives and antispasmodics. A hypodermic of morphia, 20 to 30 minutes before gauging the bladder capacity, is very useful. The local reflex irritability may be done away with by applications of eucain or cocain to the prostatic urethra. A small catheter should be used, save in the exceptional instances in which sphincteric resistance is easily overcome and the hydrostatic method without catheter can be used under relatively low pressure. Sterile water or normal salt solution is best for distending the bladder. Antiseptic solutions, as a rule, are too irritating, and defent the very purpose for which they are used.

Whenever, in gauging bladder capacity, the urine returns at first with some degree of force, but loses this force as the test proceeds, it may be safely assumed that tumporary distension atony has been produced and the operation, so far as gauging vesical capacity at that particular séance is concerned, is a failure, and the test will require repetition.

100 State Street.

\section{PRIMARY SARCOMA OF THE ESOPHAGUS AND STOMACH.*}

WILLIAM TRAVIS HOWARD, JR., M.D.

Professor of Pathology. Western Reserve University : Pathologist to the Lakeside, City and Charity Hospitals. CLEVELAND, OHIO.

PRIMARY SARCOMA OF THE ESOPHAGUS.

Ine fact that there are only eleven cases recorded in the literature shows that this affection is rare. Most of the cases have been regarded as pathological curiosities and were reported by the following authors: Chapman, 1877 ; 'Targett, 1889 ; Stephan, 1890; Shaw. 1891; Rolleston, 1893; Albrecht, 1895; Ogle, 1896 ; Livingood, 1898; Gastpar: 1900, and Stark, 2 cases, 1900 . Besides these, Perry and Shaw, in an article on malignant tumors of the stomach, allude to two cases of sarcoma of the esophagus without, however, giving either clinical or pathologic data.

To the previously reported cases I am able to add another, that of a smooth muscle cell sarcoma of the lower end of the esophagus. The history is as follows: S. B., aged $\tilde{5} 1$, was admitted to the Cleveland City Hospital service of Dr. Hoover, August, 1900, complaining of vomiting and difficulty in swallowing. He died a few weeks later of exhaustion.

* Read at the Fifty-second Annual Meeting of the American Medical Association in the Section on Pathology and Bacteriology, and approved for publication by the Executive Committee: Drs. and approved for publication by the Exe
A. Stengel, W. S. Hall and I. Hektoen. 